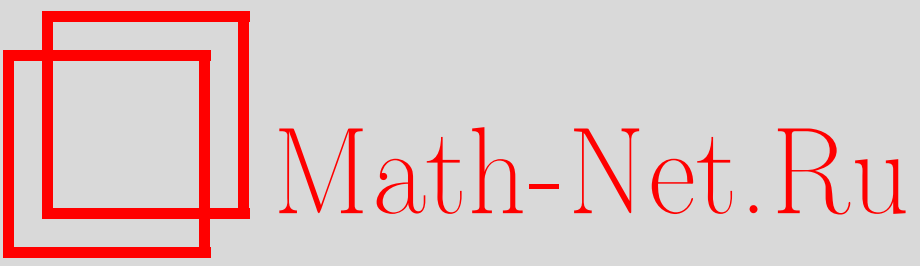

В. С. Азарин, А. А. Гольдберг, А. И. Ильинский, В. А. Марченко, Л. А. Пастур, И. В. Скрыпник, М. Л. Содин, А. М. Улановский, Г. М. Фельдман, Е. Я. Хруслов, Г. П. Чистяков, Иосиф Владимирович Островский (к 70-летию со дня рождения), УМН, 2005, том 60, выпуск 1, 186-188

DOI: https://doi.org/10.4213/rm1406

Использование Общероссийского математического портала Math-Net.Ru подразумевает, что вы прочитали и согласны с пользовательским соглашением

http: //www . mathnet.ru/rus/agreement

Параметры загрузки:

IP : 54.224 .187 .69

26 апреля 2023 г., $14: 49: 55$ 


\section{ИОСИФ ВЛАДИМИРОВИЧ ОСТРОВСКИЙ (к семидесятилетию со дня рождения)}

\footnotetext{
6 апреля 2004 г. исполнилось семьдесят лет Иосифу Владимировичу Островскому.
}

И. В. Островский родился в Днепропетровске. Способности к математике у него обнаружились в седьмом классе, когда он, вынужденньй не выходить из дома из-за болезни, увлекся чтением учебников А.П. Киселева и в течение месяца изучил школьную программу за два последующих класса. Большую поддержку в стремлении стать математиком ему оказала учительница 9-10 классов Мария Ароновна Фишкина, бывшая студентка М. Г. Крейна.

После окончания в 1951 г. средней школы в Краматорске (Донецкая область) И.В. Островский поступил на физико-математический факультет Харьковского университета. В 1954 г. Б.Я. Левин организовал на факультете научньй семинар по теории функций, и Иосиф Владимирович стал одним из его самых активных участников. После окончания университета в 1956 г. он поступил в аспирантуру, где его руководителем был

Б.Я. Левин. В 1959 г. И.В. Островский защитил кандидатскую диссертацию "Связь между ростом мероморфной функции и распределением ее значений по аргументам", а в 1965 г. - докторскую "Асимптотические свойства целых и мероморфных функций и некоторые их применения". С 1958 по 1985 г. И.В. Островский работал в Харьковском университете, с 1963 г. - заведующим кафедрой теории функций. В 1986 г. он возглавил отдел теории функций Физико-технического института низких температур АН УССР, продолжая работать по совместительству в университете до 1995 г. В настоящее время он - профессор Билкентского университета в Анкаре (Турция). В 1978 г. И.В. Островский избран членом-корреспондентом АН УССР (сейчас Национальная АН Украины). В 1992 г. ему, совместно с А. А. Гольдбергом и Б. Я. Левиным, присуждена государственная премия Украины за работы по теории функций.

Основные научные результаты И.В. Островского относятся к теории целых и мероморфных функций и ее применениям к теории вероятностей, спектралшной теории дифференциальных операторов и гармоническому анализу.

В начале научной деятельности И. В. Островского центральными в его исследованиях были вопросы о связи роста мероморфной функции с распределением ее значений по аргументам. Результаты, полученные им в этой области, существенно усиливают теоремы Л. Бибербаха, Р. Неванлинны, М.Г. Крейна, А. Эдрея. Недавно эти резултаты Иосифа Владимировича нашли применение в его исследованиях свойств функций с ограничениями на расположение корней частных сумм или остатков их рядов Тейлора.

К началу 60 -х годов относятся первые публикации И. В. Островского по аналитической теории вероятностей. В 1962 г. он доказал гипотезу Ю. В. Линника, касающуюся классической теоремы Й. Марцинкевича. Для этого он использовал доказанньй им усиленньй вариант теоремы Вимана-Валирона о поведении целой функции в окрестности точек, где ее модул достигает максимального значения на окружности. Это усиление нашло приложение в аналитической теории 
дифференциальных уравнений. Впоследствии Иосиф Владимирович неоднократно возвращался к этому кругу вопросов и получил различные обобщения этого резултата.

Важные результаты были получены И. В. Островским в арифометике вероятностных законов. Ему удалось значительно развить метод Ю. В. Линника и получить существенное продвижение в проблеме описания класса $I_{0}$ вероятностных распределений, не имеющих неразложимых компонент. Результаты И.В.Островского по арифметике вероятностных законов вносят существенный вклад в теорию характеристических функций. В известных монографиях Е. Лукача, Б. Рамачандрана, посвященных теории характеристических функций, значительное место уделено изложению его результатов.

В цикле работ 80-х годов И. В. Островский (совместно с А.А. Голшдбергом и рядом своих учеников) подробно исследовал асимптотическое поведение целшх характеристических функций и распределение их корней. В частности, было получено описание индикаторов целых характеристических функций конечного порядка и нулевых множеств целых характеристических функций.

В середине 70-х годов И.В. Островский совместно с В. А. Марченко исследовал спектр оператора Хилла. Теоретико-функциональной основой этих работ явилась параметризация класса вещественных целых функций с вещественными \pm 1 -точками с помощью конформных отображений верхней полуплоскости на верхнюю полуплоскость с вертикальными разрезами. В настоящее время эта параметризация играет принципиальную роль в теории операторов Штурма-Лиувилля, а также при исследовании экстремальных свойств целых функций экспоненциального типа.

Большой цикл работ И.В. Островского посвящен исследованию классов комплекснозначных мер, в которых имеет место однозначная определенность сужениями на полуось. Оказалось, что этот круг вопросов тесно связан со многими классическими задачами теории функций: теоремой Титчмарша о свертке, второй основной теоремой Неванлинны-Картана для аналитических вектор-функций, факторизацией функций в классах Харди и другими

Остановимся подробнее на работах, выполненных И. В. Островским в последнее десятилетие. Цикл его работ посвящен изучению такого эффекта: определенные геометрические условия на нулевые множества отрезков $s_{n}(z):=\sum_{k=0}^{n} a_{k} z^{k}$ или остатков $t_{n}(z):=\sum_{k=n+1}^{\infty} a_{k} z^{k}$ формалшного степенного ряда $f(z):=\sum_{k=0}^{\infty} a_{k} z^{k}$ влекут ограничения на рост функции, задаваемой этим рядом. Отметим, что изучению распределения нулей отрезков степенных рядов посвящено болшшое количество работ, в то время как связь между распределением нулей остатков ряда аналитической функции и ее ростом не была изучена. В 1913 г. Д. Пойа доказал, что если при всех достаточно болшших $n$ отрезки $s n$ имеют только отрицательные нули, то $f(z)$ - целая функция нулевого порядка. В работах И. В. Островского этот результат углублялся и обобщался в различных направлениях. В частности, он получил следующий аналог теоремы Пойа для остатков ряда: если при достаточно болшших $n$ у остатков ряда $t_{n}$ целой функции $f$ все нули лежат на отрицательной полуоси, то $\log M(r, f)=O\left((\log r)^{2}\right), r \rightarrow \infty$, причем эта оценка точна. Оказалось, что если только у двух остатков ряда нули лежат на конечной системе лучей (или на конечной системе радиусов, если функция аналитична в круге), то это также влечет оценки сверху на рост $f$. Другие обобщения теоремы Пойа, полученные И. В. Островским в работе, совместной с Н.А. Желтухиной, касаются случая, когда последователшность коэффициентов $\left\{a_{k}\right\}$ кратно-позитивна.

Другое направление исследований И. В. Островского в это десятилетие связано с изучением зависимости между частотой осцилляций вещественной функции или распределения и гладкостью ее преобразования Фурье. Отправной точкой этих исследований явилась гипотеза Дж. Хиггинса и В. Уолкера о том, что в классе функций Винера-Пэли (т.е. в классе целых функций экспоненциального типа, суммируемых с квадратом на вещественной оси) нет неосциллирующих, т.е. таких функций, все производные которых имеют только конечное число вещественных нулей. В совместных работах И. В. Островского и А.М. Улановского эта гипотеза была опровергнута, и класс неосциллирующих функций был подвергнут глубокому изучению. Исследуемьй вопрос оказался тесно связанным с известным в аналитической теории вероятностей принципом, согласно которому если преобразование Фурье положительной интегрируемой функции или конечной (положительной) меры гладко в нуле, то оно гладко на всей вещественной оси. В частности, согласно теореме П. Леви, Д. А. Райкова и Й. Марцинкевича если преобразование Фурье конечной меры аналитически продолжается на интервал $(0, i r)$ комплексной плоскости, то оно допускает 
аналитическое продолжение в полосу $\{t: 0<\operatorname{Im} t<r\}$. И. В. Островским и А.М. Улановским получены далеко идущие обобщения этой теоремы, в частности, на растущие функции и распределения.

Упомянем еще несколько из работ Иосифа Владимировича, выполненных им совместно с другими математиками, которые дают представление о широте его математических интересов: с С. Коцем, А. Хайфави, М.Б. Эрдоганом об аналитических и асимптотических свойствах плотностей с характеристическими функциями $\left(1+|t|^{\alpha}\right)^{-1}(0<\alpha<2)$, введенных в 1953 г. Ю. В. Линником; с Р. Джонсом и Й. Розенблаттом по эргодической теории; с Ф. Б. Паковичем и М.Г. Зайденбергом о теореме единственности для полиномов; работы с В.И. Мацаевым и М. Л. Содиным, дающие новые подходы к классическим задачам о преобразовании Гильберта; с А.М. Улановским и С. Гергюн о справедливости представления Пуассона и его обобщений гармонических в полуплоскости функций при условиях на рост в полуплоскости, значительно более слабых, чем в классических теоремах, и, как следствие, о новом варианте теоремы Титчмарша о свертке.

Сказанное вьше далеко не исчерпывает весь спектр резултатов И.В. Островского, число научных публикаций которого превосходит 150. Он является автором двух монографий: "Распределение значений мероморфных функций" (в соавторстве с А.А. Голшдбергом) и "Разложения случайных величин и векторов" (в соавторстве с Ю.В. Линником). Использовав текст докторской диссертации скончавшегося Н.В. Говорова, он также подготовил к печати монографию Н.В. Говорова "Краевая задача Римана с бесконечньм индексом".

Сорок лет И. В. Островский учил математике студентов и аспирантов в Харьковском университете. Болшшой педагогический талант Иосифа Владимировича ярко проявился в его лекциях. Лекции Иосифа Владимировича выделяются ясностью и четкостью изложения. Этот стиль впечатляет также читателя публикаций его работ. Самые сложные рассуждения Иосиф Владимирович излагает с максимальной доступностью. Можно только сожалеть, что эти курсы лекций до сих пор не изданы.

Много внимания уделял И. В. Островский руководимому им семинару по аналитическим вопросам теории вероятностей. Влияние Иосифа Владимировича на всех участников этого семинара чрезвьчайно велико.

Велик вклад И. В. Островского в дело организации математической жизни Харькова. Он президент Харьковского математического общества. В течение многих лет он являлся членом редколлегии журнала "Теория функций, функционалшньй анализ и их приложения", издававшегося в Харькове с 1966 по 1993 г., а затем заместителем главного редактора нового харьковского математического журнала "Математическая физика, анализ, геометрия". В настоящее время он является главньп редактором этого журнала.

Под руководством И.В. Островского написали и успешно защитили кандидатские и докторские диссертации 23 его ученика. Его ученики работают во многих странах: США, Канада, Норвегия, Португалия, Израил, Турция.

Увлеченньй своим делом, Иосиф Владимирович заражает своей энергией окружающих. Благотворное влияние научных контактов с ним испытали не только математики, работавшие под его руководством, но и многочисленные коллеги в разных математических центрах СССР и СНГ, во Франции, Турции, Израиле, Швеции, США. Отзывы И. В. Островского о диссертациях как официального оппонента, рецензии на статьи не были формальными документами, они содержали важные замечания и указания, интересные постановки новых задач.

Многие знают Иосифа Владимировича как бессменного капитана многодневных походов по Волге, Десне, Суре, Вороне, Юрузани и другим рекам и помнят, как его спокойная уверенность и опыт поддерживали мокрых новичков, павших духом после первого пробоя лодки. Впрочем, аварии случались редко.

Мы желаем Иосифу Владимировичу доброго здоровья и сил, многих лет такой же вдохновенной творческой жизни.

В. С. Азарин, А. А. Гольдберг, А.И. Ильинский, 